\title{
Editorial:
}

\section{Reaching a Turning Point after 30 Years of Reform}

\author{
ImAI, Yasuo* \\ Editor-in-chief
}

The year 2009 is certain to mark a milestone in Japan's political history. The Liberal Democratic Party, which was continually in power after 1955 except for a short interruption from 1993 to 1994, lost a great number of seats in the year's general election, and a new administration appeared, featuring the Democratic Party of Japan. At present it is unknown what influence this administrative change may have on the government's educational policy and eventually on education in Japan as a whole. Nevertheless, a major factor in the defeat of the LDP was that the Japanese people voiced their criticism against the neoliberalist reform policy the party had proceeded with, and the educational policy played a significant role in such neoliberalist reform. In consideration of these respects, 2009 is likely to represent a turning point in the development of education in Japan.

In my essay, 'From 'Postwar Pedagogy' to 'Post-Cold War Pedagogy': An Overview of the History of Educational Theory in Japan 1945-2007', which was included in issue No. 2 of Educational Studies in Japan: International Yearbook, I stated that educational theory in postwar Japan had a turning point in 1979: After the Second World War, educational theory configured itself as a science that critically reflects the post-war educational system, which first underwent a reorganization before it actually began to function around the year 1960. It was in 1979 that the systematization of postwar pedagogy was culminated, while the educational system, which postwar pedagogy had examined as an object of analysis and criticism, manifested its functional failures in the form of a series of pathological phenomeon in education like school bullying or violence, clearly representing and revealing a division between theory and reality.

The educational system in Japan then entered a restructuring phase. It was the four reports prepared by the Ad Hoc Council on Education (AHCE, 1984-87) that determined the direction for restructuring education in Japan. The AHCE's policy, which was geared toward the deregulation and privatization of education,

*The University of Tokyo

e-mail: imaiyapa@gmail.com 
was backed by the tide of globalization resulting from the end of the Cold War, and eventually developed into the recent neoliberalist reform policy. However, the 30year-old restructuring of the educational system is now reaching another turning point.

Assessing changes over time is difficult for anyone who lives in that particular era. This is because the way in which someone views how things changes also changes over time. It is therefore difficult for him or her to comprehend changes as they are occurring. The 30 year period that has passed since 1979 corresponds precisely in length to the period during which the postwar educational system was launched, culminated, and declined (1949-1979). It is no wonder if we can observe as significant qualitative and quantitative changes occurring during the latest 30 years as those that had occurred during the preceding 30 years.

To name a few typical changes, the professional authority in education, which had been established and trusted to a certain extent in the postwar system, was (in negative terms) shaken and eventually dismantled based on economic efficiency, or (in positive terms) the authority was relativized from the standpoint of the common sense of citizens. The framework of the nation-state, which had become the major foundation for post-war education, has been relativized, and education has become associated with international comparison and competition in the same way that the economy has. Provided that a new paradigm of thinking originated after 1979 , and that the restructuring movement orchestrated by the neoliberalist policy has reached a turning point today, a new framework is needed to comprehensively analyze and evaluate the restructured post-cold-war education system, and to advance to a new stage of thinking.

To do so, it is of course necessary to clearly understand the changes that are occurring in the domain of education. However, to avoid becoming complacent in the face of changes and merely confirming what has already happened, it is also necessary to clarify the structural characteristics of education that distinguish the domain of education from other domains, so that educational research is able to reformulate and to establish a base of knowledge which will make it possible to more appropriately understand and manage the changing educational domain.

This issue features a collection of papers under the title of "Educational Studies in Japan: The Present State and its Challenges," which attempt to identify and acknowledge several fields represented in educational studies as viewed from unique and timely perspectives. The issue also includes several reports entitled "Social Changes in East Asia and Education Reforms," which are based on the international symposium as part of the annual meeting of JERA in August 2009. With these scholarly works this issue will mark the first step in the establishment of the above-mentioned new knowledge about education. 